\title{
Tribological Behaviour of Lm25 Aluminium Alloy Reinforced With Nano Aluminium Oxide
}

\author{
R. Surendran ${ }^{1}$, Dr. A. Kumaravel ${ }^{2}$, S. Vignesh ${ }^{3}$ \\ ${ }^{1}$ Assitantnt Professor, Department of mechanical engineering, Government college of engineering, salem, \\ ${ }^{2}$ Professor, Department of Mechanical Engineering, K.S.Rangasamy college of technology, Namakkal, \\ ${ }^{3}$ M.E-CAD, Department of Mechanical Engineering Government college of engineering,salem,
}

Abstract: The LM25/Al2O3 nano composites were fabricated using a die casting method .The LM25 Aluminum alloy was reinforced with Al2O3 nan particles $0 \mathrm{wt} . \%, 1 \mathrm{wt} . \%, 1.5 \mathrm{wt} \%, 2.5 \mathrm{wt} \%$ and $5 \%$. The composites were characterized by Wear, Tensile, Hardness and Impact tests were carried out in order to identify mechanical properties. . The results reveal that die casting could be an economical route for the production of nano composites. Increasing the volume of fraction and/or reducing the size of Al2O3 nano particulates increase both the tensile and yield strength of the nano composites and reducing the wear

Keywords: MMNC, Nano Alumina, die casting, Mechanical properties.

\section{Introduction}

Metal-matrix Nano composite materials have emerged as a viable alternative to overcome the limitations of metal matrix composites; however nano composites are challenging to produce as structural components due to difficulties in attaining a homogeneous distribution of the nano phased particles.

A nano composite is a multiphase solid material where one of the phases has one, two or three dimensions of less than 100 nanometers $(\mathrm{nm})$, or structures having nano-scale repeat distances between the different phases that make up the material. In the broadest sense this definition can include porous media, colloids, gels and copolymers, but is more usually taken to mean the solid combination of a bulk matrix and nano-dimensional phase(s) differing in properties due to dissimilarities in structure and chemistry. The mechanical, electrical, thermal, optical, electrochemical, catalytic properties of the nano composite will differ markedly from that of the component materials. Particulate reinforcement by employing double layer feeding die casting technique proves to be a promising technique in developing MMNC

2.1

\section{Experimental procedure}

\section{Materials}

Metal matrix nano composites can also define as reinforced metal matrix composites. This kind of composites can be classified as continuous and non continuous reinforced materials. One of the important nano composites is Carbon nanotube metal matrix composites which is emerging new materials that are being developed to take advantage of the high tensile strength and electrical conductivity of carbon nanotube materials. Critical to the realization of CNT-MMC possessing optimal properties in these areas are the development of synthetic techniques that are (a) economically producible, (b) provide for a homogeneous dispersion of nanotubes in the metallic matrix, and (c) lead to strong interfacial adhesion between the metallic matrix and the carbon nanotubes. In addition to carbon nanotube metal matrix composites, boron nitride reinforced metal matrix composites and carbon nitride metal matrix composites are the new research areas on metal matrix nano composites.

Another kind of nano composite is the energetic nano composite, generally as a hybrid sol-gel with a silica base, which, when combined with metal oxides and nano-scale aluminum powder, can form super thermite materials 


\begin{tabular}{|c|c|}
\hline Chemical Composition & LM25 \\
\hline Copper & o.1 Max \\
\hline Magnesium & $0.2-0.6$ \\
\hline Silicon & $6.5-7.5$ \\
\hline Iron & 0.5 max \\
\hline Manganese & 0.5 Max \\
\hline Nickel & 0.1 Max \\
\hline Zinc & 0.1 Max \\
\hline Lead & 0.1 Max \\
\hline Tin & 0.05 Max \\
\hline Titanium & 0.2 Max \\
\hline Aluminium & Remainder \\
\hline
\end{tabular}

Table -1

\subsection{Processing}

The Aluminum alloy (LM25) was heated in a graphite crucible under controlled argon environment. The furnace heating temperature was increased to $750^{\circ} \mathrm{C}$, hold for 30 minutes until Aluminum alloy melted completely

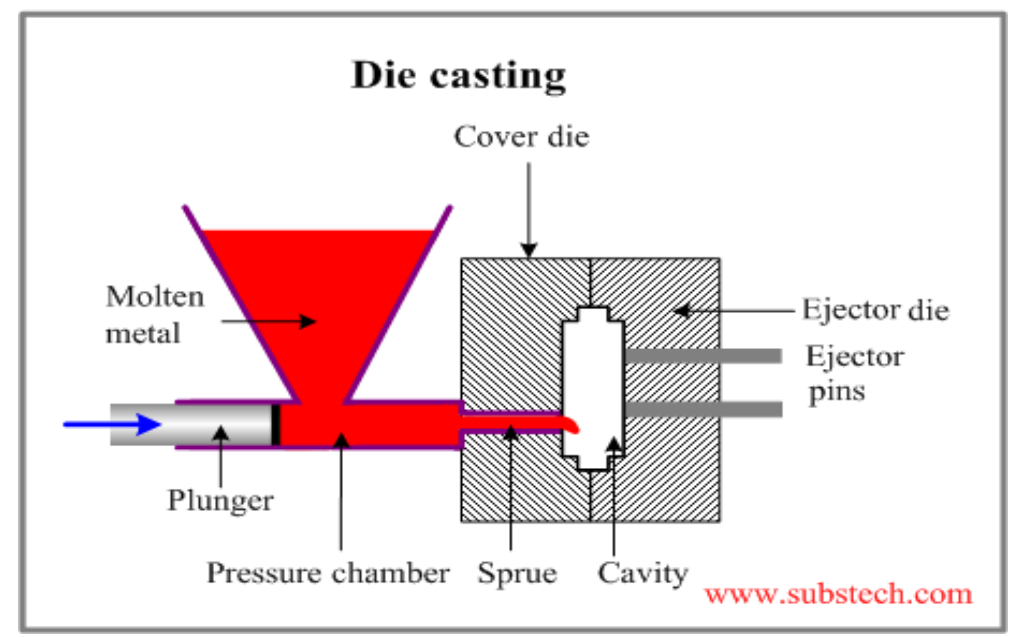

Fig 1

Aluminum dross then removed from the surface of the molten metal. Weighted amounts particulate of zirconium oxide preheated to $750^{\circ}$ were added continuously to the molten metal through the side of vortex created by mechanical stirring by the stir impeller. The optimum stirring speed of $450 \mathrm{rpm}$ was determined and selected prior to this experiment. This is to avoid excessive gas content that resulted from over agitating of melts, which led to unacceptable porosity content in the casting product (Hashim et al., 2002). The impeller and stirring rod was coated with liquid alumina so as to avoid any metals contamination to the molten metal.Stirring was carried out to facilitate both incorporation and uniform distribution of particulate Aluminium Oxide in the molten metal. The composite melt was stirred for 5 minutes then immediately cast into a permanent mould in gravity die. The solidified $\mathrm{Al} / \mathrm{Al}_{2} \mathrm{O}_{3}$ metal matrix composites (MMC), which were taken out from the mould. Separate samples for tensile strength, hardness, wear resistance, impact and corrosive resistance at 0 wt. $\%$, 1 wt. $\%, 1.5$ wt. $\%, 2.5$ wt. $\%$ and $5 \%$ were produced

\subsection{Wear Testing}

Wear tests were performed using a DUCOM pin on disc tripmeter. The pin was an $8 \mathrm{~mm}$ diameter single crystal $\mathrm{Al}_{2} \mathrm{O}_{3}$ - LM25 MMNC ball which was held down stationary on the flat face of the test piece disc under a $10 \mathrm{~N}$ load initially. The disc velocity is maintained at $0.1 \mathrm{~m} / \mathrm{s}$ in unlubricated, open air environment. Before and after each test, the specimen and the discs were cleaned using the acetone and dried up in the open air to avoid any contaminations. Experimental parameters were tabulated in Table 2. Also the temperature change in the specimens at the ends of the wear test was measured using the digital temperature indicator with $0.1^{\circ} \mathrm{C}$ accuracy. 
TABLE IIEXPERIMENTAL PARAMETERS OF WEAR TEST

\begin{tabular}{|c|c|}
\hline Pin Length & $30 \mathrm{~mm}$ \\
\hline Pin Diameter & $8 \mathrm{~mm}$ \\
\hline Load & $10-20 \mathrm{~N}$ \\
\hline Track Diameter & \multicolumn{2}{|c|}{$60-90 \mathrm{~mm}$} \\
\hline Sliding speed & $3.665 \quad \mathrm{~s}(1000 \mathrm{RPM})$ \\
\hline
\end{tabular}

Table-2

\subsection{Mechanical Testing}

The mechanical behaviour of the materials, specimens were prepared for tensile tests. A cylindrical rod specimen of $\varnothing 15$ is subjected to a tensile load using the Universal Testing Machine (UTM). Test data were used to find the breaking and the ultimate load corresponding to the MMNC samples.

The specimens were prepared for measuring hardness tests by polishing them with suitable grades of emery and etching them finally. Rockwell hardness test was carried out with $1 / 16$ " steel ball indenter with minor load of $10 \mathrm{kgF}$ and major load of $90 \mathrm{kgF}$. Aluminium Oxide

The specimens were prepared for measuring the impact strength of LM25 and reinforcement of

\section{5 .Scanning electron microscopy (SEM)}

The microstructure and chemical composition of the phase present in the test samples were studied using a JOEL JSM 5900LV scanning electron microscope equipped with an oxford INCA energy dispersive /(eds) system. The polished samples were firmly held on the sample holder using a double -sided carbon tape before putting them inside the sample chamber. The SEM operated at an accelerating voltage of 5-20kv.

\subsection{MMNC Samples}

\section{Results and Discussions}

The MMNC samples prepared shows presence of porosity reduces with increase in the percentage of reinforcement. The presence of porosity reduces as the reinforcement increases since the interfacial bonding between the aluminium matrix and the $\mathrm{Al}_{2} \mathrm{O}_{3}$ particulates is high for higher percentage of reinforcements.

\subsubsection{Hardness samples}

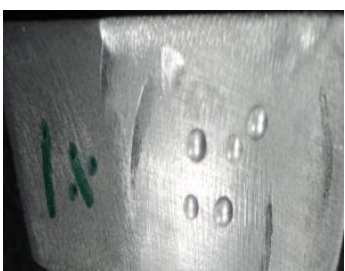

(a)

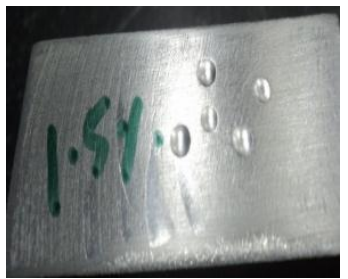

(b)

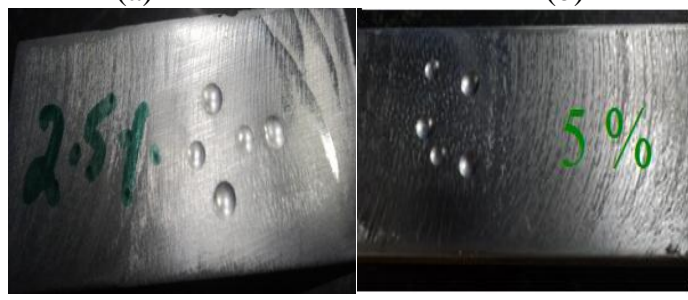

(c)

(d)

Fig. 2 Hardness samples (a) MMNC with $1 \% \mathrm{Al}_{2} \mathrm{O}_{3}$, (b) $\mathrm{MMNC}$ with $1.5 \% \mathrm{Al}_{2} \mathrm{O}_{3}$, (c) MMNC with $2.5 \%$ $\mathrm{Al}_{2} \mathrm{O}_{3}$.(d) MMNC with $5 \% \mathrm{Al}_{2} \mathrm{O}_{3}$ 


\subsection{Tensile test samples}

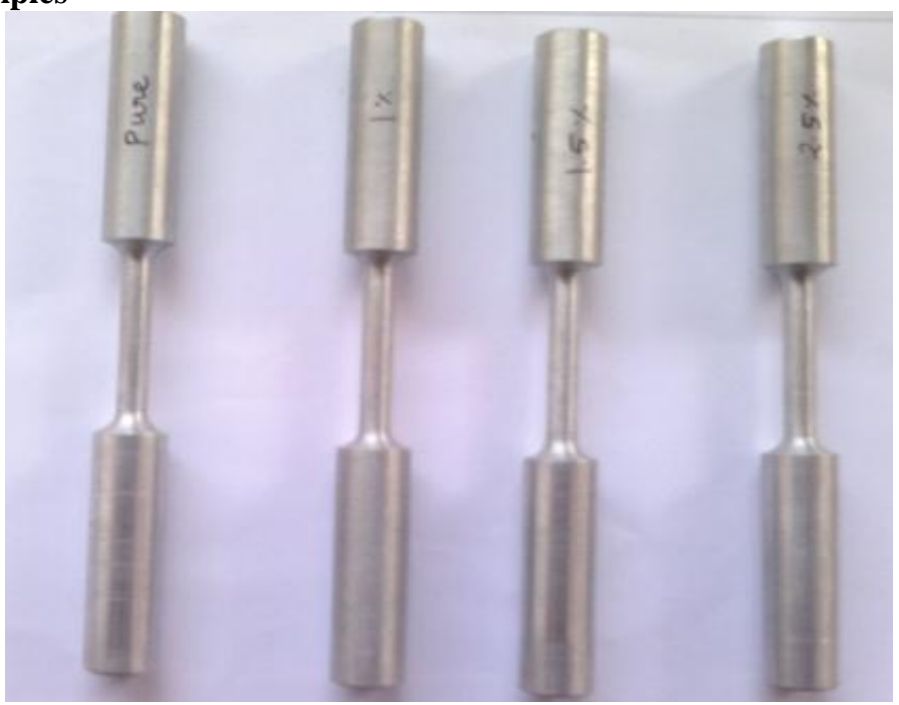

Fig 3

\subsubsection{Impact samples}

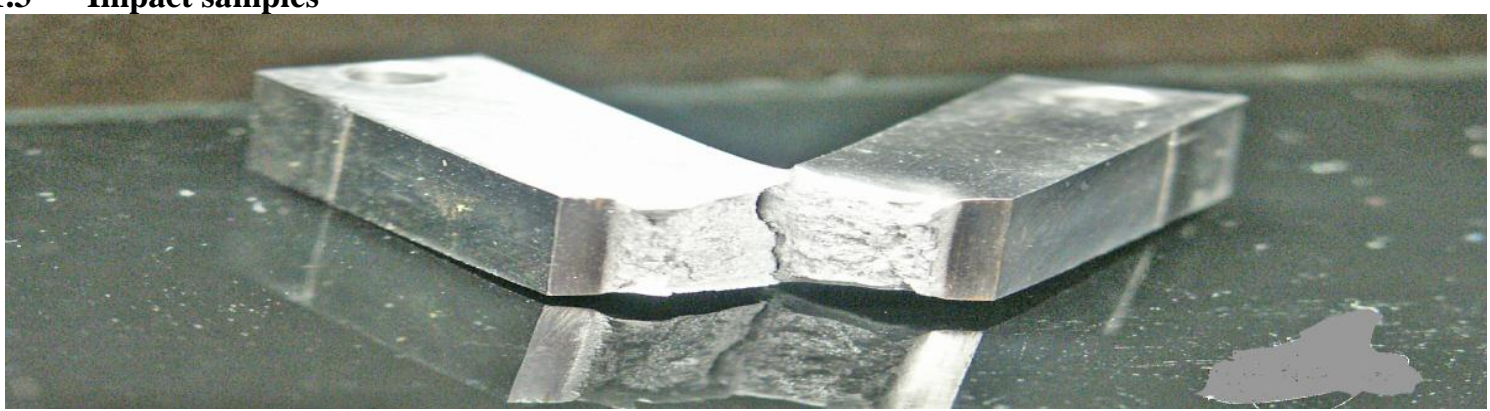

\subsubsection{Wear samples}

Fig 4

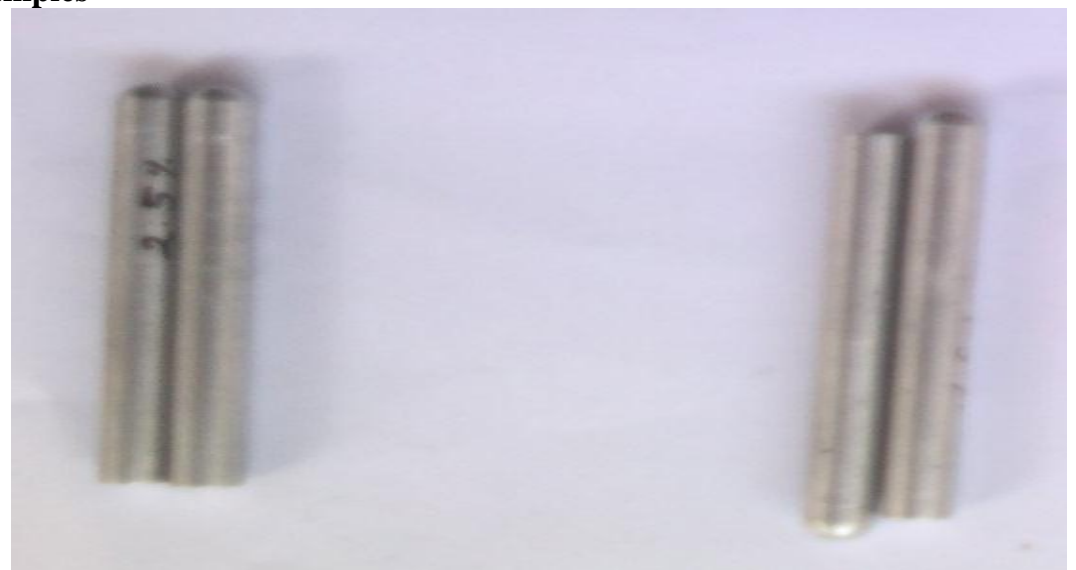

Fig 5

\subsection{Wear Characteristics}

Pin-on-disc dry sliding wear test results with pins of pure Aluminium reinforced with up to $1 \%, 1.5 \%$, $2.5 \%$ and $5 \%$ weight of $(40 \mathrm{~nm})$ nano-sized alumina showed that wear rate decreases with increasing percentage of reinforcement. The volumetric wear rates of Aluminium and its composites are plotted against the time to the wear in micrometer. It is immediately apparent that there is consistent improvement in wear resistance with increasing amounts of reinforcement. This corresponds directly to the rise in hardness and strength of the composites with reinforcement level, and agrees with Archard's equation that the wear of a material is inversely proportional to its hardness. The $5 \% \mathrm{Al}_{2} \mathrm{O}_{3}$-reinforced MMNC, being the best performer shows an improvement in the wear resistance of 1.2 times at the lowest speed of $1 \mathrm{~m} / \mathrm{s}$, and more importantly, up to 1.9 times under the 
higher-speed, and thus, more severe sliding conditions. The wear rates are plotted against the time and are shown in Fig. 7.

There is a gradual reduction in the wear rates of all the specimens over a fairly wide range of sliding velocities, from 1 to $7 \mathrm{~m} / \mathrm{s}$. In this series of tests under a $20 \mathrm{~N}$ load, the optimum speed for these materials appears to be around $7 \mathrm{~m} / \mathrm{s}$, beyond which, the wear rates begin to rise.

The results of this study have shown that nano-sized alumina particulates $1 \%, 1.5 \%, 2.5 \%$ and $5 \%$ volume are able to bring appreciable improvement to the wear resistance of pure aluminium matrix alloy, especially under higher sliding speeds. The small volume fraction of reinforcement used presently is significant because the earlier studies have found there exists an optimum level of reinforcement for a given particulate size and sliding condition, beyond which, despite an increase in hardness, results in wear rates comparable to or even higher than the unreinforced material

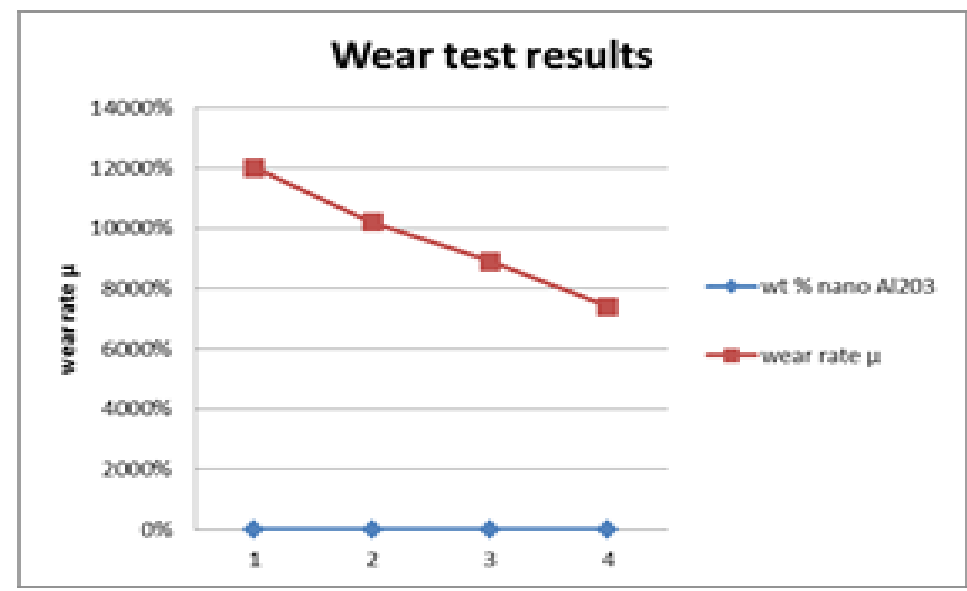

Fig. 6 Volumetric Wear rates of pure matrix alloy and MMNC

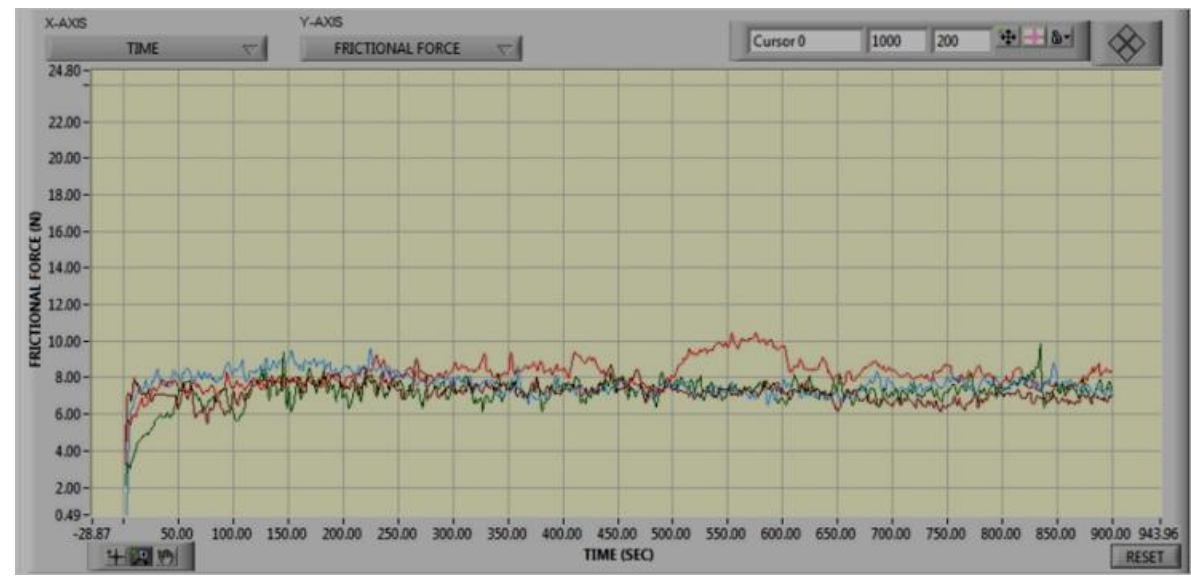

Fig. 7 Frictional force resistance offered by LM25 and MMNC

The resistance to the frictional force was also being studied. The results shown in Fig. 7 revealed that composites offer less frictional loss as they are able to withstand high temperatures induced due to the friction and the better wear property was also studied. The temperatures at the end of the wear test were measured by placing the thermocouple probe in the small drilled hole near the end of the sample. It was observed to be $83^{\circ} \mathrm{C}$ in case of matrix alloy and $76^{\circ} \mathrm{C}$ for $\mathrm{MMNC}$ with $5 \% \mathrm{Al}_{2} \mathrm{O}_{3}$ reinforcement.

\subsection{Mechanical test results}

It was observed that the MMNC samples with higher percentage of reinforcement shows higher hardness. The hardness values of the test samples were shown in Fig. 5. In case of tensile tests, the results revealed that breaking strength and ultimate tensile strength was at a peak for MMNC with $2.5 \%$ nano alumina reinforcements. The property of the material changes from ductility to brittle nature on addition of reinforcements in further. The tensile test, Hardness test and wear test results plots were shown in Fig. 8.Fig 9.Fig 10 


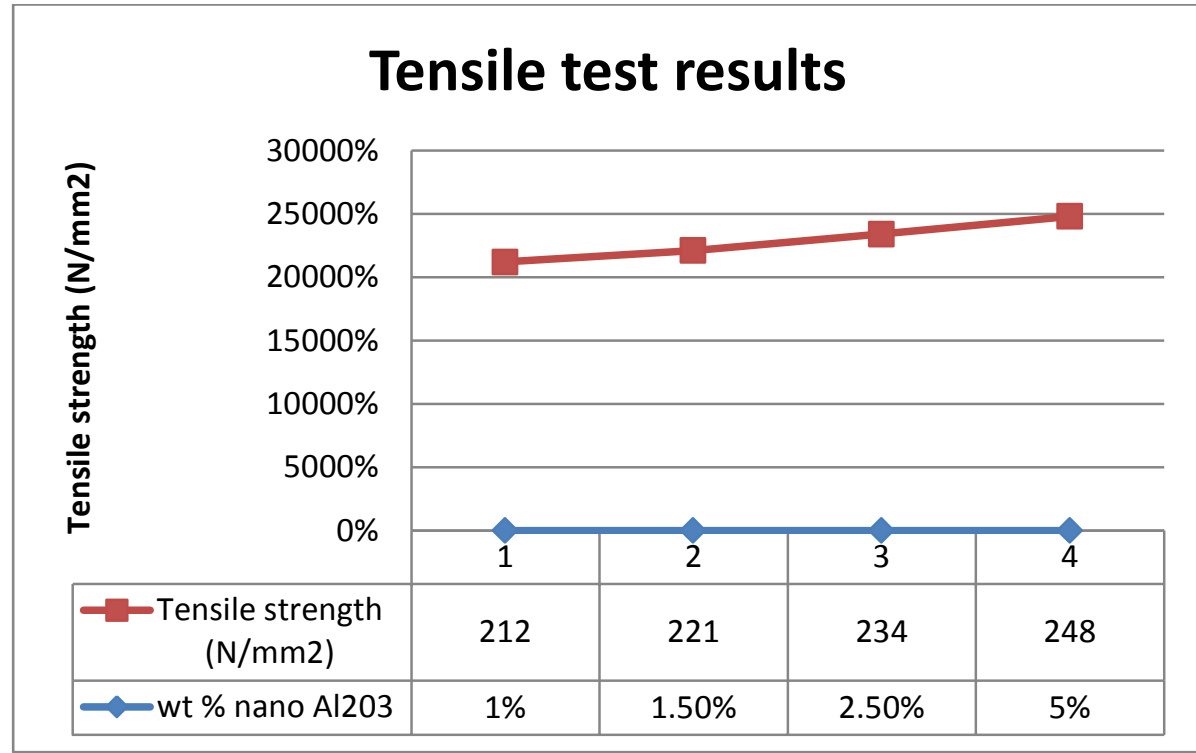

Fig. 8 Tensile test plots results of LM25 and MMNC

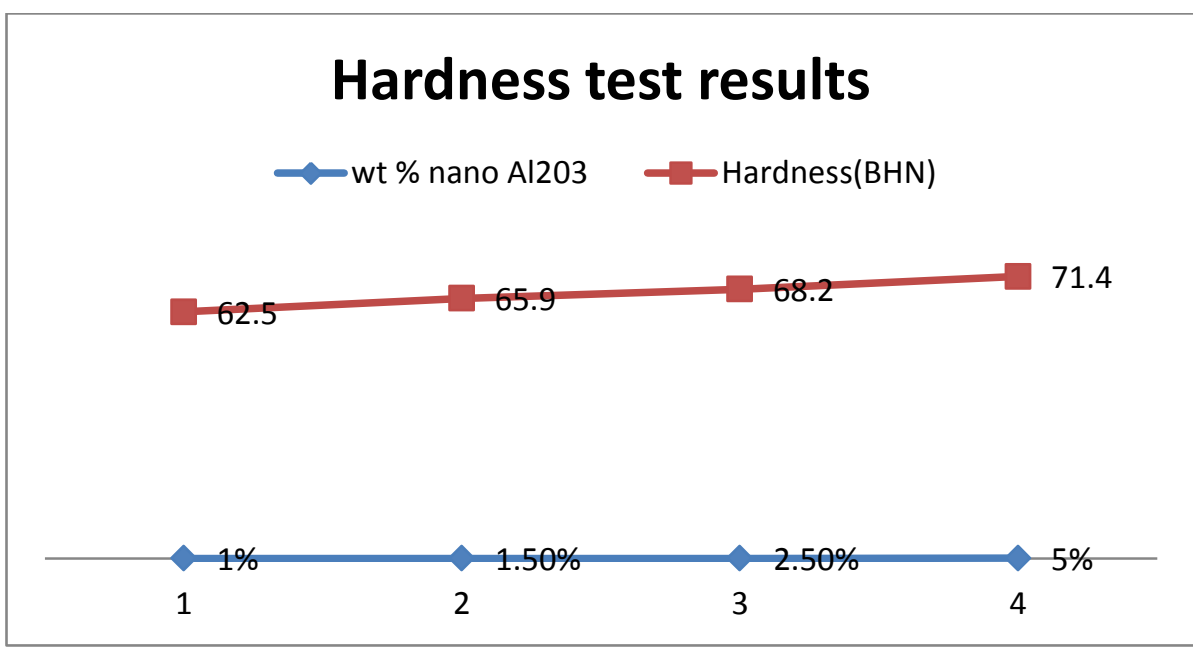

Fig. 9 Hardness survey results of LM25 and MMNC

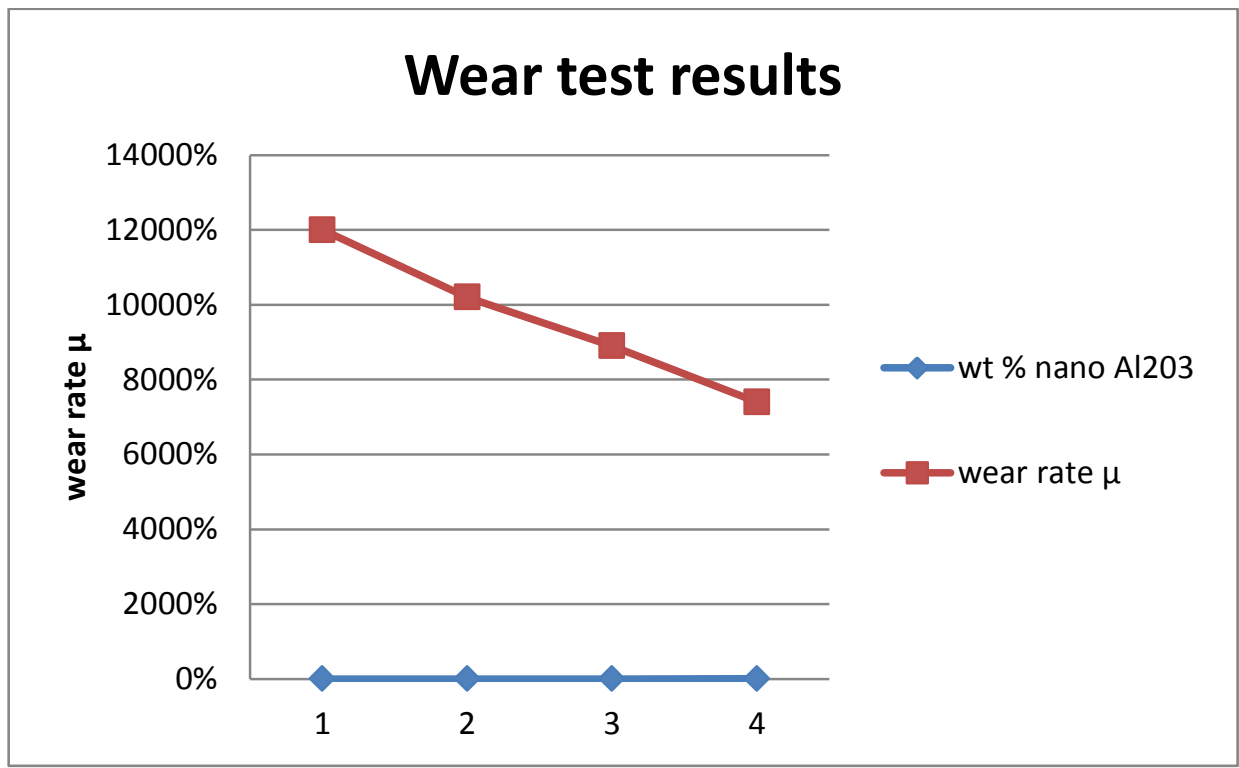

Fig. 10 Volumetric Wear rates of matrix alloy and MMNC 


\subsection{SEM (Scanning electron microscopy)}

(A)

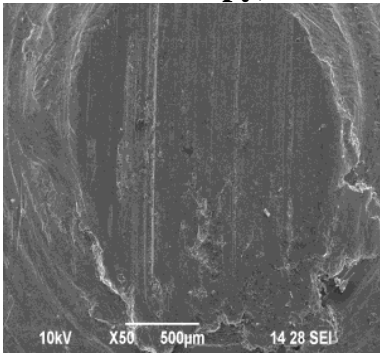

MMNC WITH $1 \% \mathrm{AL}_{2} \mathrm{O}_{3}$

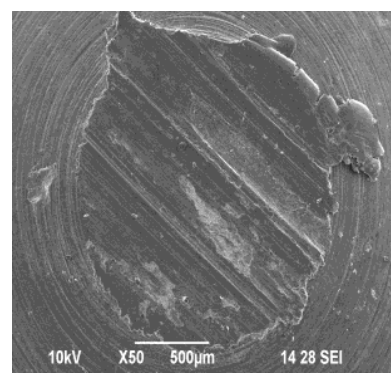

(C) $\mathrm{MMNC}$ with $2.5 \% \mathrm{Al} 2 \mathrm{O} 3$

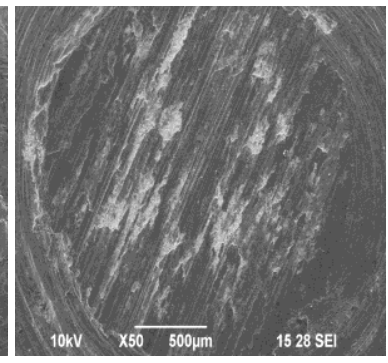

(B) MMNC WITH $1.5 \%$ AL2O3

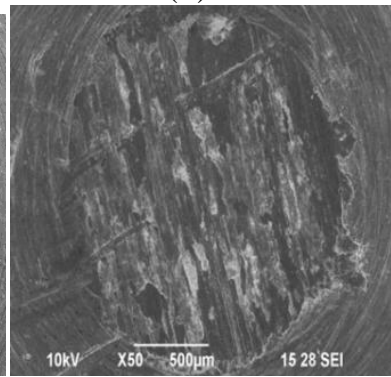

(D) MMNC with 5\% $\mathrm{Al} 2 \mathrm{O} 3$

\section{Conclusions}

$1 \%, 1.5 \%$ and 2.5 and $5 \%$ Nano Alumina reinforcement are fabricated and the MMNC are prepared in the form of Blanks, Rods and Billets from these the test specimen has been produced and examined for Hardness test, Impact test, Tensile test and wear test

From these results The MMNC thus prepared exhibits good mechanical properties like hardness; Tensile strength and impact resistance and tribological properties like wear resistance compared to the ethnic materials. Beyond the critical load the MMNC may exhibit the same characteristics as that of base alloy.

The LM25 Al. Alloy reinforced with 5\% of $\mathrm{Al}_{2} \mathrm{O}_{3}$ MMNCgives the better results when compared to the all other types of metal matrix composites thus produced and tested. And the Combined results were tabulated in the below table

\begin{tabular}{|l|l|l|}
\hline Mechanical properties & LM25 Al. Alloy & $\begin{array}{l}\text { LM25 Al. Alloy Reinforced with 5\% } \\
\text { of } \mathbf{A l}_{\mathbf{2}} \mathbf{O}_{\mathbf{3}}\end{array}$ \\
\hline Hardness & $55 \mathrm{BHN}$ & $71.4 \mathrm{BHN}$ \\
\hline Ultimate Tensile Strength & $192 \mathrm{~N} / \mathrm{mm} 2$ & $248 \mathrm{~N} / \mathrm{mm}^{2}$ \\
\hline Impact strength & $9 \mathrm{Nmm}$ & $37.4 \mathrm{Nmm}$ \\
\hline Wear rate & $120 \mu \mathrm{m}$ & $72 \mu \mathrm{m}$ \\
\hline
\end{tabular}

Table -3 Mechanical properties of LM25 Al. Alloy reinforced with 5\% Alumina

\section{References}

[1]. Granger C (1994), "Dry Machining’s Double Benefit”, Machinery and Production Engineering, Vol.152(3873), 14-20.

[2]. Zhang Xueping, GaoErwel and Richard Liu C (2009), "Optimization of Process Parameters of Residual Stresses for Hard Turned Surfaces", Journal of Materials Processing Technology, Vol. 209(9), 4286-4291.

[3]. Quteriro J C, Pina J C, Saoubi R M, Pusavec F and Jawahir I S (2008), “Analysis of Residual Stresses Induced by Dry Turning of Difficult - to - Machine Materials”, CIRP Annals -Manufacturing Technology, Vol. 57(1), 77-80.

[4]. Quteriro J C, Dias A M, Lebrun J L and Astakhov V P (2002), "Machining Residual Stresses in AISI 316L Steel and their Correlation with the Cutting Parameters", Machining Science and Technology", Vol. 6(2), 251-270.

[5]. S.Das, "Development of Aluminium Alloy Composites for Engineering Applications", Trans. Indian Inst. Met., vol. 57, No. 4, pp. 325-334, Aug. 2004

[6]. Hao Yu, "Processing Routes for Aluminium based Nano-composites", Master of Science thesis, Worchester Polytechnic Institute, Worchester, MA, Apr. 2010.

[7]. S.F.Hassan, M.Gupta, "Development of high performance magnesium nano-composites using nano- $\mathrm{Al}_{2} \mathrm{O}_{3}$ as reinforcement", Materials Science \& Engineering A, vol. 392, pp. 163-168, 2005.

[8]. Ramesha.D, SanthoshKumar.B, Madhusudan.M, BharathShekar.H.R, "Temperature Distribution analysis of Aluminium Composite and Cast Iron Brake Drum using Ansys", IJEST, issue 2, vol. 3, pp. 281-292, Apr. 2012.

[9]. Yoshio Jimbo, Takahiro Mibe, "Development of High Thermal Conductivity Cast iron for brake rotors", Material Experiment Department, Nissan Motors Co., Ltd.

[10]. A.A.Adebisi, M.A.Maleque, M.M.Rahman, "Metal Matrix Composite Brake Rotor: Historical Development and Product Life Cycle Analysis", IJAME, vol. 4, pp. 471-480, Dec. 2011

[11]. Peter T.B. Shaffer, Hand book of High Temperature Materials, 1st ed., New York, USA: Plenum Press, 1964. 